\title{
INTERLOCUCְ̃̃ES POSSÍVEIS ENTRE LINGUAGEM E APROPRIAC̣ÃO DE CONCEITOS CIENTÍFICOS NA PERSPECTIVA DE UMA ESTRATÉGIA DE MODELAGEM PARA A ENERGIA ENVOLVIDA NAS TRANSFORMAÇÕES QUÍMICAS
}

\author{
Vinícius Catão de Assis Souza* \\ Rosária Justi**
}

RESUMO: Atualmente, existe uma tendência na qual o ensino de Ciências estaria centrado na compreensão sobre a natureza e os processos através dos quais o conhecimento científico se desenvolve. Nesse contexto, o envolvimento dos alunos em atividades de modelagem emerge como parte essencial de uma abordagem de ensino mais interativa e dialógica. Assim, uma estratégia de modelagem para o ensino do tema energia envolvida nas transformaçoes químicas foi proposta, sendo aplicada a um grupo de alunos da $2^{\circ}$ série do Ensino Médio de uma escola Pública Federal de Belo Horizonte. Neste artigo são apresentados alguns aspectos importantes que fundamentaram essa estratégia de ensino, assim como alguns dos resultados de uma investigação sobre a aprendizagem dos alunos, particularmente aqueles relacionados à linguagem.

Palavras-chave: Ensino Fundamentado em Modelagem; Linguagem; Transformações Químicas.

\section{POSSIBLE DIALOGUES BETWEEN LANGUAGE AND SCIENTIFIC CONCEPTS APPROPRIATION FROM A MODELLING-BASED STRATEGY FOR THE TEACHING OF ENERGY ASSOCIATED WITH CHEMICALS CHANGES}

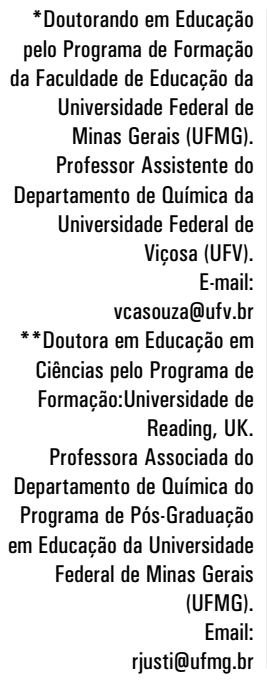

*Doutorando em Educação pelo Programa de Formação da Faculdade de Educação da Universidade Federal de Minas Gerais (UFMG). Professor Assistente do Departamento de Química da Universidade Federal de Viçosa (UFV) E-mail: vcasouza@ufv.br **Doutora em Educação em Ciências pelo Programa de Formação:Universidade de Reading, UK.

Professora Associada do Departamento de Química do Programa de Pós-Graduação em Educação da Universidade Federal de Minas Gerais (UFMG). Email: rjusti@ufmg.br

ABSTRACT: Nowadays, there is a trend in focusing science teaching on the understanding of the nature and processes through which scientific knowledge develops. In this context, students' involvement in modellingbased teaching activities emerges as an essential part of a more interactive and dialogical approach to teaching. Thus, a modelling-based strategy for the teaching of the topic energy associated with chemicals changes was elaborated. This strategy was applied to a group of high school sophomore students of a public school in Belo Horizonte. This paper presents some important aspects that served as a base for this teaching strategy, as well as some of the results of an investigation into students learning, especially those related to language.

Keywords: Modelling-based Teaching; Language; Chemical Changes. 


\section{INTRODUÇÃO}

\section{As armadilhas da linguagem na construção do conceito de energia, calor e temperatura: os múltiplos desafios para a apropriação do conhecimento em sala de aula de Ciências}

Energia é um termo usado com diversos significados na linguagem coloquial e que aparece em todas as disciplinas ligadas às Ciências Naturais, com diferentes interpretações por parte de professores e alunos. Nos distintos contextos de ensino, é curioso percebermos que a energia envolvida nos processos metabólicos, na fotossíntese e nas transformações químicas, em geral, é entendida de diferentes maneiras. Na Química, por exemplo, verificam-se muitas confusões conceituais na compreensão da energia térmica envolvida em transformações químicas (SOUZA, 2007).

Auth e Angotti (2001) afirmam que energia é um conceito unificador nas Ciências, incorporando tanto as mudanças entre as formas energéticas manifestadas, como a conservação dessas formas nos sistemas. Além disso, reúne potencial para interligar tópicos de diferentes áreas do conhecimento, favorecendo o estabelecimento de relações em nível interdisciplinar. Para esses autores, os conhecimentos científicos deveriam estar menos fragmentados, sendo necessário buscar conexões entre os diversos conceitos relevantes a fim de favorecer a aprendizagem, além de estruturar os conhecimentos de forma a se priorizar as unificações e sínteses, sem negligenciar o papel fundamental das análises. Nessa linha de raciocínio, é importante ressaltarmos que o entendimento de como se processam as transformações de energia é fundamental para o entendimento de inúmeros processos vitais, como o metabolismo dos seres vivos.

Em relação à literatura da área de ensino de Ciências, constatamos a presença de várias pesquisas realizadas com o objetivo de permitir aos professores e alunos uma melhor compreensão dos aspectos fundamentais relativos ao conceito de energia, sobretudo a partir das concepções iniciais inerentes a essa temática. Dentre os vários trabalhos, destacamos os de Aguiar (1999), Coelho (2009), Henrique (1996), Higa (1988), Pérez-Landazábal, Favieres, Manrique e Varela (1995), Souza Filho (1987) e Trumper (1991). Alguns desses estudos apontam resultados similares com relação às concepções de energia presente no senso comum, com destaque para energia: (i) como causa ou produto de um processo; (ii) associada a atividades humanas (antropocêntrica); (iii) associada ao movimento e (iv) como sinônimo de força ou fonte de força.

Além destes trabalhos, Souza Filho (1987) sintetiza algumas outras características da energia relacionadas pelos alunos: (i) algo presente em todos os fenômenos que ocorrem na natureza e com o homem; (ii) algo em potencial nos objetos (energia potencial); (iii) algo ligado ao movimento dos objetos (energia cinética); (iv) algo substancial/concreto; (v) algo que se perde e se adquire e (vi) algo 
que pode se apresentar de diferentes maneiras (como energia gravitacional, elétrica, magnética, luminosa, sonora, eólica, nuclear, térmica, química etc.).

Henrique (1996), Higa (1988), Pérez-Landazábal et al (1995), Silva, Neto e Carvalho (1998) e Trumper (1991), em pesquisas desenvolvidas com alunos de idades entre 15 e 18 anos, encontraram diferentes características para o conceito de energia, sintetizadas a seguir: (i) energia como causa para que ocorra um processo (por exemplo, energia produz calor e fogo); (ii) energia como produto final de um processo (por exemplo, óleo consome oxigênio e produz energia na forma de calor); (iii) transformação de energia (por exemplo, energia elétrica é transformada em calor, que aquece o filamento da lâmpada incandescente, emitindo luz); (iv) energia como propriedade da matéria (capacidade de produzir trabalho através da força); (v) energia associada a calor (sinônimo de aquecimento); (vi) energia como algo material, ou seja, armazenada em determinados corpos e transferida em certos processos (ideia de energia como ingrediente ou depósito); (vii) energia como algo que se conserva; (viii) energia como algo que não se conserva (por exemplo: "produzir energia/ consumir energia") e, por fim, (ix) energia associada ao homem (ideia antropomórfica).

Em relação às concepções alternativas apresentadas sobre os conceitos de calor, temperatura e energia por alunos com idades entre 15 e 18 anos, alguns autores destacam que elas podem dificultar a aprendizagem do significado de energia envolvida nas transformações químicas. Muitas delas podem estar relacionadas aos fatos de os alunos: (i) apresentarem dificuldades de estabelecer relações entre conceitos abstratos como calor, temperatura e energia (COHEN \& BEN-ZVI, 1992); (ii) pensarem nas transformações químicas como adição, cola de reagentes para formar produtos, e não como interação (BEN-ZVI, EYLON, \& SILBERSTEIN, 1987); (iii) possuírem uma visão estática das partículas, com pouco ou nenhum entendimento sobre como as transformações químicas ocorrem em nível submicroscópico (BOO, 1998); (iv) terem dificuldades em entender o significado das transformações químicas e dos processos endotérmicos e exotérmicos associadas a elas (DE VOS \& VERDONK, 1986) e (v) desconhecerem, total ou parcialmente, a origem do aquecimento ou resfriamento percebido em alguns processos químicos caracterizados com exotérmicos ou endotérmicos (BOO, 1998).

Além desses trabalhos de grande relevância para a temática em questão, vale ressaltar que a Termoquímica é um dos tópicos presentes no currículo escolar em diversos países cujo ensino e aprendizagem tem-se revelado problemático, conforme enfatizado por Boo (1998), Griffiths e Preston (1992), Mulford e Robinson (2002) e Teichert e Stacy (2002).

Considerando a multiplicidade de ideias apresentadas pelos alunos em diferentes situações, é pertinente destacarmos que os professores parecem não conhecer um modelo curricular ${ }^{1}$ adequado para a explicação do que seja a energia envolvida nas transformações químicas. Tal dificuldade é bastante compreen- 
sível, considerando-se todos os aspectos relativos à complexidade de trabalhar com um tema de vasta extensão conceitual e abstração, como energia. Porém, a ideia vinculada ao armazenamento de energia tem sido difundida com frequência nos meios escolares, tanto por professores quanto em livros didáticos. Tal associação, quando apresentada de forma descuidada e sem uma reflexão sobre a sua abrangência no campo científico, pode gerar um entrave na construção do conceito desvinculado do termo "armazenamento". Isso porque se falamos que a energia pode ser armazenada, assumimos, a princípio, que sabemos claramente o que ela é - "como um queijo armazenado no frigorifico", na pitoresca imagem criada por John Benyon. A partir dessa imagem, Benyon (1990) pergunta: "como a energia é armazenada no objeto?" e "onde a energia é armazenada no objeto?" - questões que um professor de Física ou de Química provavelmente não saberá responder de forma objetiva sem antes passar por longas elucubrações.

Independente das inquietudes que o estudo dessa temática traz à tona, algo que não se pode contestar é o fato de a energia ser um conceito abstrato. Sendo assim, Warren (1986) nos apresenta outro questionamento: "como se pode, então, armaz̧enar uma abstração?”. E, comparando energia com os números - outra abstração - "como se pode armazenar um número?". Segundo Benyon (1990), podese evidentemente armazenar objetos através de números ou quantidades de objetos correspondentes a números, mas não os números em si. Sendo assim, sugere-se que a ideia do armazenamento de energia decorre do fato de ela ser tratada linguisticamente não como um conceito físico abstrato, mas como algo concreto, como um fluido ou um combustível que possa ser armazenado ou transferido de um corpo a outro.

Em consonância com as ideias expressas anteriormente, McClelland (1989) apresenta uma discussão também bastante oportuna, com o intuito de favorecer a compreensão de tais relações: se algo será armazenado em sentido metafórico, deverá estar associado a algo material que possa ser armazenado fisicamente. Assim, podemos armazenar diferentes materiais como combustíveis e livros; mas não faz sentido falar em armazenar energia como falamos em armazenar informações. Isso porque, conforme destaca Renato dos Santos ${ }^{2}$ em um texto sobre a abrangência do conceito de energia no senso comum, um livro não contém informações, mas apenas marcas de tinta sobre o papel. Cabe a um leitor, que aprendeu a reconhecer aquelas marcas (símbolos, letras e palavras), associá-las a conceitos e dar sentido às informações do livro. Se o leitor não tiver familiaridade com a língua na qual o livro está escrito e a simbologia ali representada, não será capaz de realizar esse processo de apropriação do significado da mensagem expressa. Pelo mesmo motivo, um computador acoplado a um scanner não é capaz de ler uma página impressa. O que ele faz é, através de um programa de reconhecimento de símbolos e por meio de códigos, traduzir as marcas de tinta em gravações magnéticas num disco rígido do computador. Quem não souber ler nem usar um computador não consegue se apropriar da informação de nenhuma das duas formas de armazenamento. Por isso, 
McClelland (1989) destaca que é preferível reservar a palavra "armazenar" para entidades físicas, como combustíveis, e falar de energia apenas em termos de processos de transformação e trocas entre sistemas.

No mesmo sentido, Feynman (2005) apresenta em uma de suas conferências a seguinte visão sobre a conservação da energia na natureza:

Existe um fato ou, se você preferir, uma lei que governa todos os fenômenos naturais conhecidos até agora. Não se conhece nenhuma exceção a essa lei - ela é exata, pelo que sabemos. A lei chama-se conservação da energia. Segundo ela, há certa quantidade, denominada energia, que não muda nas múltiplas modificações pelas quais passa a natureza. Trata-se de uma ideia extremamente abstrata, por ser um princípio matemático; diz que há uma grandeza numérica que não se altera quando algo acontece. Não é a descrição de um mecanismo ou de algo concreto; é apenas um fato estranho de que podemos calcular certo número e, quando terminamos de observar a natureza em suas peripécias e calculamos de novo, ele é o mesmo. (FEYNMAN, 2005, p. 91)

No senso comum, por exemplo, existem inúmeras concepções que diferem dos conceitos aceitos cientificamente e, em se tratando do conceito de energia, há muitos termos utilizados inadequadamente, de modo especial em conversas informais, sobretudo quando se usa o termo com acepções místicas. No âmbito da Ciência, incoerências conceituais similares chegam a ser extrapoladas para alguns textos didáticos e paradidáticos. É comum observarmos que, em muitos momentos, aparecem termos impróprios, como por exemplo: energia gravitacional ao invés de força gravitacional; energia química da molécula ou energia de atração entre os átomos no lugar de força de coesão ou atração entre os átomos. Além disso, o calor é frequentemente apresentado como uma forma de energia e não como energia em trânsito graças a um gradiente de temperatura e, finalmente, as palavras força e movimento são utilizadas indiscriminadamente como sinônimos de energia.

Assim, os resultados encontrados e as considerações apresentadas em diferentes pesquisas apontam que as noções fundamentais de energia não são triviais de serem tratadas no dia a dia escolar. Uma série de dificuldades relacionadas à aprendizagem do conceito de energia parece estar presente nas relações de ensino e aprendizagem estabelecidas na escola, sendo reproduzidas com frequência no ensino. Isso pode estar relacionado com a formação dos professores, que muitas das vezes não são ensinados à luz das questões da linguagem e das metodologias adequadas para se tratar alguns assuntos fundamentais, sobretudo pela sua abrangência na Ciência.

Considerando os aspectos destacados pelas diferentes pesquisas aqui citadas, emerge a necessidade de rever o ensino da temática em questão buscando propor metodologias que possam ser mais eficazes na compreensão conceitual da Ciência de modo a favorecer o desenvolvimento do conhecimento teórico e prático relativo à energia, com destaque para o contexto da Química, foco de nosso interesse a priori. 
Nesse sentido, é importante chamar a atenção para o desafio que os professores enfrentam ao trabalhar com temas de grande abrangência conceitual, dentre os quais se destaca a energia. Isso porque o uso desses conceitos é feito de forma indiscriminada e pragmática em nossa sociedade, o que pode contribuir para que os alunos reforcem suas ideias intuitivas em relação aos diferentes conteúdos estudados, apresentando dificuldades na construção/aceitação da ideia científica. Cabe aos professores, então, estabelecer uma articulação das ideias dos alunos rumo a um construto conceitual que esteja alicerçado nos aspectos científicos, no qual as concepções prévias dos alunos possam ser (re)estruturadas em meio às novas ideias estabelecidas no processo de ensino. Isso favoreceria a superação de alguns entraves epistemológicos, de modo a transformar os possíveis "degraus" inter e transdisciplinares em "rampas" de acesso ao conhecimento científico. Atualmente, acreditamos que o ensino fundamentado em modelagem, no qual ocorrem interações mais dialógicas, pode favorecer tal articulação.

O processo de construção de modelos e sua relação com a aquisição e apropriação do conhecimento em sala de aula: diálogos possíveis entre a linguagem e o fazer Ciência.

Nas discussões atuais relacionadas à didática das Ciências, algumas propostas de mudança no ensino têm enfatizado a necessidade do desenvolvimento de atividades que favorecem o engajamento dos estudantes na resolução de problemas, considerando uma perspectiva sociointeracionista nas aulas de Ciências.

Bakhtin, quando se refere à dimensão constitutiva da linguagem, destaca que é no discurso e pelo discurso que os conhecimentos são elaborados, de modo que

\footnotetext{
... a consciência adquire forma e existência nos signos criados por um grupo organizado no curso de suas relações sociais. Os signos são o alimento da consciência individual, a matéria de seu desenvolvimento, e ela reflete sua lógica e suas leis. A lógica da consciência é a lógica da comunicação ideológica, da interação semiótica de um grupo social. Se privarmos a consciência de seu conteúdo semiótico e ideológico, não sobra nada. (BAKHTIN, 1992, p. 35-36)
}

Nesse sentido, o ensino baseado na construção de modelos e na sociointeração favorecida por esse tipo de estratégia pode apresentar um potencial para promover o aprendizado participativo, com ricos contextos que encorajam os debates entre os alunos, em que estes trabalhem de maneira colaborativa no processo de construção dos significados, conceitos e representações (BARAB, HAY, BARNETT \& KEATING, 2000). Além disso, esse processo de ensino permite ao aluno aprender sobre modelos, sua construção e, consequentemente, sobre a construção da Ciência, uma vez que uma das mais importantes atividades dos cientistas é construir, elaborar, testar e validar modelos em um ambiente dialógico, que favoreça a constante discussão das ideias na busca pela 
legitimação das mesmas. Nesse contexto, temos como pressuposto que aprender se relaciona ao processo de construir significados. Ensinar, por sua vez, seria oportunizar essa construção por meio de atividades que alicercem essa dinâmica.

Vários estudos têm mostrado que a utilização de modelagem no ensino de Ciências, na perspectiva de promover a construção do conhecimento, contribui de modo relevante para o desenvolvimento de uma aprendizagem significativa. Dentre as pesquisas realizadas na área do ensino de Ciências, destacamos, por exemplo, Barab et al (2000), Barbosa (2003), Buty e Mortimer (2008), Collins e Gentner (1987), Maia e Justi (2009), Mendonça e Justi (2009), Nersessian (1999), Souza e Justi (2010), Vosniadou (2002), dentre outras.

Além disso, a proposta de ensino baseada na utilização de modelos é corroborada pelas diretrizes apresentadas nos Parâmetros Curriculares Nacionais para o Ensino Médio - PCNEM - da área de Ciências da Natureza, Matemática e suas Tecnologias. Neste documento, está destacado que uma das competências gerais a serem desenvolvidas pelos alunos diz respeito aos domínios da investigação e compreensão, ou seja, ao uso de ideias, conceitos, leis, modelos e procedimentos científicos. Mais especificamente, espera-se que o ensino de Química forneça condições para o aluno "reconhecer, utilizar, interpretar e propor modelos para situações problema, fenômenos ou sistemas naturais ou tecnológicos" (BRASIL, 2000, p. 32).

Nesse contexto, a introdução dos alunos em atividades de construção de modelos pode permitir que eles desenvolvam conhecimentos específicos por meio dos próprios modelos criados e, acima de tudo, da interação proporcionada pelos debates com o grupo. Além disso, eles terão oportunidades de avaliar tais modelos, podendo desenvolver um potencial crítico em relação aos modelos utilizados no ensino e na Ciência. Por fim, terão a oportunidade de compreender o processo de construção dos mesmos - sob um aspecto geral e na Ciência (JUSTI \& GILBERT, 2002).

Dessa maneira, o envolvimento de estudantes nesse tipo de atividade se mostra bastante promissor como uma metodologia de ensino interativa que está de acordo com a perspectiva construtivista, de modo que (i) as concepções prévias dos alunos são extremamente relevantes, pois é a partir delas que os modelos são construídos e/ou reformulados e (ii) o aluno é um sujeito ativo na construção e apropriação de novos conhecimentos.

Finalmente, os resultados das pesquisas citadas anteriormente evidenciam que o envolvimento dos alunos em atividades de modelagem ajuda a promover um entendimento que vai além da memorização de fatos e informações. Isto tende a favorecer o desenvolvimento de um conhecimento flexível e crítico, que pode ser aplicado e transferido para diferentes situações e problemas (CLEMENT, 2000). Além disso, favorece o trânsito dos alunos entre o pensamento e a linguagem, de modo que 
... a relação entre o pensamento e a palavra não é uma coisa mas um processo, um movimento contínuo de vaivém do pensamento para a palavra, e vice-versa. Nesse processo, a relação entre pensamento, linguagem e a palavra passa por transformações que, em si mesmas, podem ser consideradas um desenvolvimento do sentido funcional. O pensamento não é simplesmente expresso em palavras; é por meio delas que ele passa a existir. Cada pensamento tende a relacionar alguma coisa com outra, a estabelecer uma relação entre as coisas. Cada pensamento se move, amadurece e se desenvolve, desempenha uma função, soluciona um problema. Esse fluxo de pensamento ocorre como um movimento interior através de uma série de planos. (VYGOTSKY, 1987, p. 108)

Nesse sentido, Silva e Aguiar (2008) destacam que, de acordo com Vygotsky, a "palavra" é um instrumento para a formação de conceitos. A linguagem, por sua vez, perfaz o meio primordial do pensamento, sendo indissociável da sua forma mais elaborada, que é o pensamento verbal. Wertsch (1997) destaca que os processos mentais podem ser compreendidos e apropriados de forma significativa apenas se entendermos os instrumentos e os signos que os permeiam.

A interação em sala de aula e os pares que dela participam (alunos e professores) são peças fundamentais nas construções conceituais, tendo em vista que

... é na dinâmica dos processos interpessoais, nas trocas dialógicas com outras pessoas em torno de objetos, nas instâncias de produção e compreensão da palavra, que o aluno desenvolve o significado desta. (GÓES, 1997, p. 21)

Nesse sentido, Mortimer (1998) destaca que

... implementar uma perspectiva dialógica em sala de aula não significa apenas dar voz ao aluno e à aluna. Significa também, contemplar as vozes da linguagem cotidiana e dos contextos sociais e tecnológicos onde a Ciência se materializa, na construção do discurso científico escolar da sala de aula. (MORTIMER, 1998, p. 117)

Além disso, envolver estudantes em atividades de modelagem tende a favorecer que eles percebam os modelos como importantes ferramentas na prática científica e conheçam a estreita relação dos mesmos com o desenvolvimento de teorias (no sentido de que modelos podem ser usados como instrumentos de exploração tanto no domínio prático quanto no teórico, como mediadores entre teoria e fenômeno (MORRISON \& MORGAN, 1999)). Assim, para entender Ciência, é desejável que os alunos saibam como os modelos são construídos e validados, reconhecendo de forma dialógica e interativa os diferentes caminhos trilhados para se desenvolver o conhecimento científico, até que ele seja instituído e aceito por um determinado grupo. 


\section{A PESQUISA}

\section{Objetivos e Metodologia do Trabalho}

Considerando-se os pressupostos apresentados anteriormente, esse artigo busca discutir uma interlocução entre a linguagem e a construção de conhecimento científico por meio de uma estratégia de modelagem para o ensino do tema energia envolvida nas transformacões químicas, descrita por Souza e Justi (2010).

A referida estratégia de ensino foi aplicada aos alunos da segunda série do Ensino Médio de uma Escola Pública Federal de Belo Horizonte. Os dados foram coletados a partir de materiais escritos produzidos pelos alunos durante todo o processo, gravações em vídeo de todas as aulas e notas de campo.

A partir da análise dos dados escritos e da participação dos alunos nas discussões, um estudo de caso foi redigido para cada grupo, permitindo-nos discutir a contribuição de atividades de modelagem na aprendizagem. A análise desta situação de ensino nos conduziu a conclusões que merecerem algumas discussões mais pormenorizadas, sobretudo quando consideramos algumas classificações de processos termoquímicos e suas relações com as percepções térmicas a eles associados (processos endotérmicos e exotérmicos). No presente artigo, alguns trechos dos estudos de caso elaborados serão usados em nossa análise.

De início, devemos ressaltar que tal estratégia de ensino tinha como objetivo favorecer aos alunos o desenvolvimento de uma percepção relacionada ao processo de rearranjo de átomos, inerente a toda transformação química, permitindo-lhes elaborar relações com os aspectos energéticos que permeiam tal processo. Para isso, foram criados contextos que favorecessem aos alunos desenvolver suas ideias de forma gradual, (re)pensando os modelos que iam emergindo da interação favorecida pelas diversas atividades.

Ao elaborarmos a estratégia de ensino, levamos em consideração algumas relações históricas que seriam utilizadas de modo particular em determinadas situações, subsidiando a articulação de algumas ideias que proliferaram no contexto científico por longos anos e que, surpreendentemente, ainda estão bastante vívidas em nossos dias. Uma dessas ideias tem a ver com as relações substancialistas da energia que se mostram presentes em nosso dia a dia, refletindose de modo notório no contexto escolar. Tal ideia, que se apresenta discreta à primeira vista, parece estar incorporada à estrutura cognitiva dos alunos, levando-os a utilizá-la de forma indiscriminada em diferentes contextos. Por isso, foram propostas questões que permitiram aos alunos (re)estruturar suas concepções de modo dialógico, crítico e reflexivo, reformulando os modelos criados inicialmente. 


\section{Discussão dos resultados}

Mesmo após a participação em todas as atividades propostas, descritas com detalhes em Souza e Justi (2010), um considerável número de alunos ainda permanecia com as concepções substancialistas bastante evidentes em seus modelos, falas e respostas às questões avaliativas que lhes foram propostas. Um fator que pode ter influenciado na manutenção dessas ideias foi a linguagem utilizada nos diferentes contextos de ensino (falas da professora, material escrito das atividades e livro didático - mesmo que este tenha sido raramente utilizado pelos alunos durante as aulas analisadas nesta pesquisa).

Nas aulas que analisamos, a professora preocupou-se com a questão da linguagem, tentando não dar ênfase a aspectos nitidamente substancialistas às vezes presentes em sua fala. Tal fato foi observado no diálogo estabelecido pela professora com os alunos em um dos grupos de trabalho, em que ela apresentou o seguinte questionamento: "Vamos dizer... será que ele [ $\left.\mathrm{H}_{2} \mathrm{SO}_{4}\right]$ 'contém', entre aspas, esta energia potencial?". Porém, por maior que tenha sido a cautela em suas palavras, em algumas situações a ideia substancialista esteve presente nelas, como na seguinte frase: "o calor é consequência da liberação de energia...". Exemplos como esses evidenciam o quanto é difícil nos apartarmos dessas "armadilhas" da linguagem. Conforme discutimos no início deste artigo, uma palavra como libera não seria a mais adequada neste contexto, pois traz a ideia de algo que estava acondicionado fisicamente e não de algo abstrato, como a energia. Mas, em uma situação de ensino, que outra palavra poderia ser usada que não traria tal sentido? Acreditamos que nenhuma.

Percebemos, então, que nos encontramos um tanto quanto prisioneiros de nossa linguagem. Mas acreditamos que o conhecimento não se constrói com o silêncio e atitudes inertes. Ele se constrói em meio à ebulição de ideias, favorecendo uma reflexão crítica sobre o saber e uma articulação real do conhecimento por parte de quem aprende. Por isso, os erros e as vicissitudes inerentes ao ensino devem ser vistos de forma positiva pelos professores, tendo em vista que tais erros devem ser transformados em aliados para a (re)construção e apropriação do conhecimento e não como empecilhos. Isso porque tais situações podem favorecer a condução dos alunos a um pensamento mais elaborado e reflexivo, a partir do qual o saber científico vai se alicerçando em patamares bastante sólidos em relação aos distintos construtos teóricos.

Por isso acreditamos que, antes de utilizarmos essas terminologias que permitem associações substancialistas, é fundamental deixar todo o processo relacionado às transformações químicas bastante explícito para os alunos, indicando as relações envolvendo o rearranjo dos átomos e os aspectos energéticos que permeiam o processo. A partir de uma garantia de que essas ideias estão bem compreendidas, tais palavras poderiam ser usadas. Nesse sentido, as atividades de modelagem foram de grande utilidade, tendo em vista que os alunos puderam conceber o processo que permeia o rearranjo dos átomos, tendo uma ideia coe- 
rente das relações energéticas envolvidas nas transformações químicas, caracterizando o processo como endotérmico ou exotérmico em termos do saldo energético final.

Outro aspecto relacionado à questão da linguagem também merece ser ressaltado nesse contexto. Muitas vezes, cientistas raciocinam empregando analogias e palavras com sentido metafórico. Professores podem até mesmo utilizar termos semelhantes, mas um cuidado especial deve ser tomado ao enfoque dado a esses termos. Isso porque os alunos podem empregar tais termos sem demonstrar um real entendimento dos mesmos no contexto em estudo. Cientistas e professores, por sua vez, devem buscar a utilização de uma linguagem que objetive facilitar a comunicação e o entendimento com o aluno. Assim, deve-se tomar cuidado com o uso superficial de termos do tipo o calor saiu do sistema, o calor entrou no sistema, a energia está armazenada na molécula. Isso porque, se uma linguagem inadequada à concepção científica for aplicada em excesso, pode passar a ter um significado literal para os alunos, podendo gerar explicações incompatíveis com as ideias aceitas na Ciência.

Considerando-se o processo de elaboração e reelaboração de modelos presente nas atividades da estratégia de ensino aqui comentada, é importante destacarmos que, ao aplicar a estratégia de ensino a um grupo piloto, havíamos descrito o seguinte comando no quadro fornecido aos alunos para a elaboração dos modelos:

MODELO 1 - LIBERA ENERGIA

MODELO 2 - ABSORVE ENERGIA

\section{EXPLICAC̣̃̃O DOS MODELOS}

Entretanto, após inúmeras reflexões, discussões com alguns professores e também pela constatação de que tais palavras poderiam reforçar as concepções substancialistas nas respostas dos alunos, decidimos mudar a terminologia utilizada inicialmente. Para tais reflexões, muito contribuíram os questionamentos feito por uma aluna na aplicação piloto das atividades: "Como o sistema pode ter liberado calor para o ambiente se ele se aqueceu? E como pode ter absorvido calor se lá dentro ficou frio?". Tais questionamentos fizeram com que pensássemos que os termos empregados na solicitação (libera/absorve) poderiam ter levado a aluna a pensar assim. Desse modo, decidimos modificar as expressões para:

MODELO 1 - SISTEMA AQUECIDO

MODELO 2 - SISTEMA RESFRIADO

\section{EXPLICAÇ̃̃O DOS MODELOS}

Segundo Mortimer e Scott (2003), a partir dos estudos de Vygotsky e de Bakhtin, o significado de algum termo ou conceito é considerado como polissêmico e polifônico, criado na interação com o outro e, somente então, interna- 
lizado pelo indivíduo. Sendo assim, os professores devem estar bastante atentos à linguagem utilizada em sala de aula e às ideias que as palavras carregam com seus múltiplos significados. Por isso, se faz necessário permitir que na interação estabelecida em sala de aula, os alunos possam construir uma ideia coerente dos processos que permeiam as relações energéticas nas transformações químicas, compreendendo a ideia de saldo energético final, que caracterizará as transformações químicas como endotérmicas ou exotérmicas.

\section{CONCLUSÕES E IMPLICAC̣̃̃ES PARA O ENSINO DE CIÊNCIAS}

As propostas mais recentes para o ensino de Química têm como um de seus pressupostos a necessidade do envolvimento ativo dos alunos nas aulas, em processos interativos professor/aluno e aluno/aluno, em que os horizontes conceituais dos alunos sejam contemplados. Isso significa criar oportunidades para que eles expressem como veem o mundo, o que pensam, como entendem os conceitos, quais são as suas dificuldades etc. Além disso, considerando a linguagem como ferramenta do conhecimento, acreditamos que deve ser dado a ela um tratamento muito cuidadoso para que se cumpra adequadamente a sua função no ensino, levando à construção e apropriação de um conhecimento científico repleto de significado para o aluno. A Figura 1 apresenta um diagrama, baseado em Guidoni (1985), que procura sintetizar esquematicamente tais concepções e suas interrelações:

FIGURA 1 - Esquema cognitivo simplificado de construção do conhecimento científico em um indivíduo.

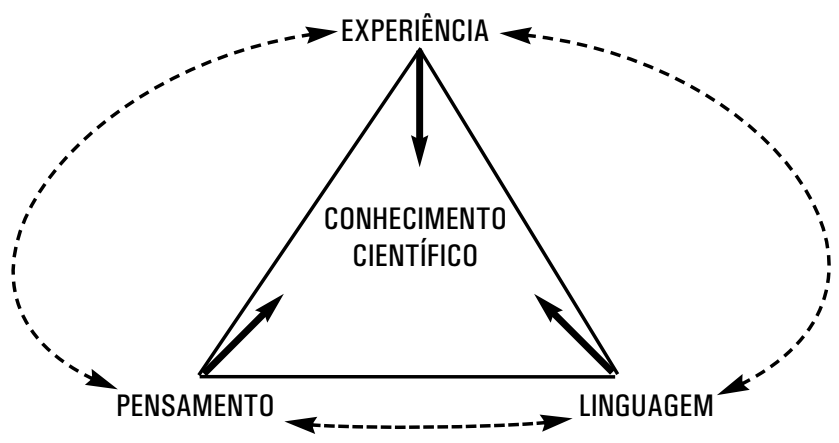

De acordo com Souza (2007), em um ensino de Química que tende a fomentar a construção do conhecimento junto aos alunos, torna-se necessário desenvolver neles a habilidade de transitar pelas vertentes do fazer científico, demonstrando-lhes as inúmeras limitações para a construção do saber, como a da linguagem usada para expressá-lo. Ou seja, é preciso discutir que, até mesmo na atividade científica, somos prisioneiros de uma rede de linguagem e vivências, com caráter altamente subjetivo, no qual eu vejo o outro e, consequentemente, 
os diferentes contextos e situações problema pela minha ótica do certo e do errado, a partir do meu julgamento. Por isso, torna-se importante para os alunos que eles próprios sejam capazes de dar um novo significado à Ciência, construindo seus próprios saberes de forma subjetiva e autônoma, sem receber nada pronto, como acontece na dinâmica proposta pelas atividades de modelagem.

No contexto de modelagem, além das questões inerentes à linguagem verbal, devemos discutir aspectos referentes às diferentes formas de representação de energia/calor utilizadas pelos alunos em seus modelos, como as setas, as aspas ao redor de algumas partículas indicando a vibração das mesmas, dentre outros aspectos representacionais frequentemente encontrados no contexto do ensino.

As setas podem ou não apresentar uma concepção substancialista, dependendo do contexto ao qual se relacionam e da percepção conceitual que os alunos apresentam em relação ao seu uso. No caso das atividades analisadas, isso foi observado, por exemplo, nas representações feitas por alguns alunos que, ao expressarem seus modelos, utilizaram frequentemente setas para representar a ideia do calor como algo físico que emana de um sistema. Tal conclusão foi corroborada pelas explicações dadas pelos alunos para os seus desenhos e nas quais palavras que carregam uma expressiva conotação substancialista foram usadas de forma descuidada, conforme discutimos anteriormente.

Ainda em relação às formas de representação, algumas dificuldades na aprendizagem dos alunos podem ter tido como causa a limitação apresentada por eles ao modelar uma ideia abstrata, como a de energia, utilizando materiais concretos (desenho, massa de modelar, palitos de madeira etc.). Por isso, buscamos enfocar nessa estratégia a criação de modelos para descrever as transformações químicas, os rearranjos de átomos associados a elas - processo passível de representação concreta - e a energia envolvida nesse processo, cujo saldo final caracteriza a transformação como exotérmica ou endotérmica.

Em termos do processo de ensino como um todo, é importante ressaltarmos, mais uma vez, o papel de uma estratégia alicerçada em modelagem no aprendizado dos alunos, com destaque para um conteúdo em que o ensino temse mostrado problemático. Como o professor não apresenta um modelo pronto aos alunos, mas algumas informações (às vezes a partir de experimentos) que os ajudem a conectar seus conhecimentos anteriores com as ideias atuais ou, ainda, que os façam repensar e modificar suas ideias anteriores, é possível que os alunos percebam limitações ou incoerências em seu modelo, buscando modificá-lo ou mesmo substituí-lo por outro mais adequado. Nesse processo, os alunos podem propor um novo modelo que seja compatível com as novas informações ou capaz de explicar uma determinada situação problema. Ao se ensinar esse tema através de atividades em que os alunos elaboram modelos, as informações apresentadas aos alunos para subsidiar o processo de modelagem (pelo professor ou pelas próprias atividades) podem fazer mais sentido para eles, visto que eles deverão realmente compreendê-las a fim de serem capazes de elaborar seus modelos. 
Finalmente, ao analisarmos a utilização desta estratégia de ensino fundamentada em modelagem, constatamos também que os alunos se envolveram bastante em todas as etapas do processo, principalmente naquelas resultantes da introdução de questões bastante desafiadoras e nos momentos em que eles defenderam seus modelos e discutiram aspectos divergentes desses em relação aos modelos apresentados pelos colegas. Nesses momentos, eles demonstraram a utilização de um raciocínio criativo e coerente com suas ideias anteriores, com as evidências e informações às quais eles tiveram acesso, e com as ideias discutidas no grupo ou entre os grupos. Como resultado, a maior parte dos alunos foi capaz de elaborar e reformular seus modelos. Assim, compactuamos com a ideia proposta por Driver, Asoko, Leach, Mortimer e Scott (1994) de que aprender Ciências não é uma questão de simplesmente ampliar o conhecimento dos jovens sobre os fenômenos - uma prática talvez denominada mais apropriadamente como estudo da natureza - nem de desenvolver ou (re)organizar o raciocínio do senso comum dos jovens. Aprender Ciências requer desafiar as ideias prévias dos alunos através de eventos inquietantes, que os permitam pensar criticamente sobre os fenômenos que lhes são apresentados. Nesse sentido, aprender Ciências requer que os alunos sejam introduzidos numa forma diferente e audaciosa de pensar sobre o mundo natural e de explicá-lo. Por isso, é desejável que eles compreendam os processos químicos para que possam se apropriar, de forma coerente e legítima, dos conceitos que permeiam os aspectos energéticos envolvidos nas transformações químicas, base para explicação de muitos fenômenos que perpassam as Ciências da Natureza. Para favorecer essa dinâmica de aprendizagens, o processo de (re)elaboração dos diferentes modelos até se construir um modelo consensual mais próximo do curricular seria favorecido pelas próprias atividades de modelagem e pelas interações dialógicas estabelecidas na sala de aula.

\section{AGRADECIMENTOS}

Ao prof. Orlando Aguiar (FaE-UFMG), pelas relevantes discussões e contribuições dadas na elaboração desse artigo e ao CNPq.

\section{NOTAS}

${ }^{1}$ Entende-se como modelo curricular as simplificações do modelo científico que constituem o currículo escolar (GILBERT, BOULTER \& ELMER, 2000).

2 O referido texto, A Energia do Senso Comum $-1^{a}$ parte, se encontra disponível no site http://files.fisica-interessante.com/energia_do_senso_comum.pdf (acessado em 08/05/2010). 


\section{REFERÊNCIAS BIBLIOGRÁFICAS}

AGUIAR, O. Calor e temperatura no Ensino Fundamental: o ensino e a aprendizagem numa perspectiva construtivista. Investigações em ensino de Ciências, v. 4, n. 1, p. 73-90, 1999.

AUTH, M. A; ANGOTTI, J. A. P. O processo de ensino-aprendizagem com aporte do desenvolvimento histórico universal: a temática das combustões. In PIETROCOLA, M. (Ed.), Ensino de Física: conteúdo, metodologia e epistemologia numa concepção integradora. Florianópolis: UFSC, 2001. p. 197-232.

BAKHTIN, M. M. Estética da criação verbal. São Paulo: Martins Fontes, 1992.

BARAB, S. A, et al. Virtual Solar System Project: Building Understanding through Model Building. Journal of Research in Science Teaching, v. 37, n. 7, p. 719-756, 2000.

BARBOSA, J. P. V. Evolução dos modelos mentais de energia. 2003. Dissertação (Mestrado) - Faculdade de Educação, Universidade Federal de Minas Gerais, Belo Horizonte, 2003.

BEN-ZVI, R; EYLON, B; SILBERSTEIN, J. Students' visualisation of chemical reaction. Educational in Chemistry, v. 24, n. 4, p. 117-120, 1987.

BENYON, J. Some myths surrounding energy. Physics Education, v. 25, n. 6, p. 314-315, 1990.

BOO, H. K. Students' understandings of chemical bonds and the energetics of chemical reactions. Journal of Research in Science Teaching, v. 35, n. 5, p. 569-581, 1998.

BRASIL. Parâmetros Curriculares Nacionais Ensino Médio Parte III - Ciências da Natureza, Matemática e suas Tecnologias. Brasília: Ministério da Educação e Cultura, 2000.

BUTY, C.; MORTIMER, E. F. Dialogical/Authoritative Discourse and Modelling in High School Teaching Sequence on Optics. International Journal of Science Education, v. 30, n. 12, p. 1635-1660, 2008.

COELHO, R. L. On the Concept of Energy: How understanding its History can Improve Physics Teaching. Science \& Education, v. 18, n. 8, p. 961-983, 2009.

COHEN, I.; BEN-ZVI, R. Students' achievement in the topic of chemical energy by implementing new learning materials and strategies. International Journal of Science Education, v. 14, n. 2, p. 147-156, 1992.

COLLINS, A; GENTNER, D. How people construct mental models. In D, Hollan; N, Quinn (Eds.), Cultural models in language and thought. Cambridge: Cambridge University Press, 1987. p. 243265.

DE VOS, W; VERDONK, A. H. A new road to reaction - Part III. Journal of Chemical Education, v. 63 , n. 11 , p. 972-974, 1986.

DRIVER, R. et al. Constructing scientific knowledge in classroom. Educational Researcher, v. 23, n. 7, p. 5-12, 1994.

FEYNMAN, R. P. Física em 12 Licões. 5 ed. Rio de Janeiro: Ediouro, 2005.

GILBERT, J. K; BOUlTER, C. J; ELMER, R. Positioning Models in Science Education and in Design and Technology Education. In J. K. Gilbert \& C. J. Boulter (Eds.). Developing Models in Science Education. Dordrecht: Kluwer, 2000. p. 3-17.

GÓES, M. C. R. As relações intersubjetivas na construção de conhecimento. In: SMOLKA, A. L. B; GOES, M. C. R. A significação nos espaços educacionais. Campinas: Papirus, 1997.

GRIFFITHS, A. K.; PRESTON, K. R. Grade-12 students' misconceptions relating to fundamental characteristics of atoms and molecules. Journal of Research in Science Teaching, v. 29, n. 6, p. 611628, 1992.

GUIDONI, P. On Natural Thinking. European Journal of Science Education, v. 7, n. 2, p. 133-140, 1985.

HENRIQUE, K. F. O pensamento físico e o pensamento do senso comum: a energia no $2^{\circ}$ grau. 1996. Dissertação (Mestrado em Ensino de Ciências) - Instituto de Física, Faculdade de Educação, Universidade de São Paulo, São Paulo, 1996.

HIGA, T. T. Conservaşão de Energia: estudo histórico e levantamento conceitual dos alunos. Dissertação de Mestrado em Ensino de Ciências. Instituto de Física, Faculdade de Educação, USP, São Paulo, 1988. JUSTI, R; GILBERT, J. K. Modelling, teachers' views on the nature of modelling, implications for the education of modellers. International Journal of Science Education, v. 24, n. 4, p. 369-387, 2002. 
MAIA, Poliana Flávia; JUSTI, Rosária. Learning of Chemical Equilibrium through ModellingBased Teaching. International Journal of Science Education, v. 31, n. 5, p. 603-630, 2009.

McCLELLAND, G. Energy in School Science. Physics Education, v. 24, n. 3, p. 162-164, 1989.

PÉREZ-LANDAZÁBAL, M. C, FAVIERES, A, MANRIQUE, M. J; VARELA, P. La energía como núcleo en el diseño curricular de la Física. Enseñanza de las Ciencias, v. 13, n. 1, p. 55-65, 1995. MENDONÇA, P. C. C; JUSTI, R. Favorecendo o aprendizado do modelo eletrostático: análise de um processo de ensino de ligação iônica fundamentado em modelagem - Parte 2. Educación Quimica, v. 20, n. 3, p. 373-382, 2009.

MORRISON, M; MORGAN, M. S. Models as mediating instruments. In M. S. MORGAN; M. MORRISON (Eds.), Models as mediators. Cambridge: Cambridge University Press, 1999. p. 10-37.

MORTIMER, E. F. Sobre chamas e cristais: a linguagem cotidiana, a linguagem científica e o ensino de Ciências. In: Ciência, Ética e Cultura na Educação. São Leopoldo: Unisinos, 1998.

MORTIMER, E. F; SCOTT, P. Meaning making in secondary science classrooms. Maidenhead: Open University Press/McGraw Hill, 2003.

MULFORD, D. R; ROBINSON, W. R. An inventory for alternate conceptions among first-semester general chemistry students. Journal of Chemical Education, v. 79, n. 6, p. 739-744, 2002.

NERSESSIAN, Nancy J. Model-Based Reasoning in Conceptual Change. In L. MAGNANI, N. J. NERSESSIAN; P. THAGARD (Eds.), Model-Based Reasoning in Scientific Discovery. New York: Kluwer and Plenum Publishers, 1999. p. 5-22.

SILVA, D; NETO, V. F; CARVALHO, A. M. P. Ensino da distinção entre calor e temperatura: uma visão construtivista. In R. NARDI (Ed.), Questões atuais no ensino de Ciências. São Paulo: Escrituras Editora, 1998. p. 61-75.

SILVA, N. S; AGUIAR, O. O uso dos conceitos de elemento e substância por estudantes do ensino fundamental: uma perspectiva de análise sociocultural. Revista Brasileira de Pesquisa em Educação em Ciências, v. 8, n. 3, p. 1-17, 2008.

SOUZA FILHO, O. M. Evolução da ideia de conservação de energia: um exemplo de história da Ciência no ensino de Física. 1987. Dissertação (Mestrado em Ensino de Ciências) - Instituto de Física, Faculdade de Educação, Universidade de São Paulo, São Paulo, 1987.

SOUZA, V. C. A. Os desafios da Energia no contexto da termoquímica: modelando uma nova ideia para aquecer o ensino de Química. 2007. Dissertação (Mestrado em Educação) - Faculdade de Educação, Universidade Federal de Minas Gerais, Belo Horizonte, 2007.

SOUZA, V. C. A; JUSTI, R. Estudo da utilização de modelagem como estratégia para fundamentar uma proposta de ensino relacionada à energia envolvida nas transformações químicas. Revista Brasileira de Pesquisa em Educaşão em Ciências, v. 10, n. 2, p. 1-26, 2010.

TRUMPER, R. Being constructive: an alternative approach to the teaching of the energy concept - part two. International Journal of Science Education, v. 13, n. 1, p. 1-10, 1991.

VYGOTSKY, L. S. Pensamento e Linguagem. 3 ed. São Paulo: Martins Fontes, 1987.

VOSNIADOU, S. Mental Models in Conceptual Development. In MAGNANI, L; NERSESSIAN, N. J; THAGARD, P. (Eds.), Model-based Reasoning in Scientific Discovery. New York: Kluwer and Plenum Publishers, 2002. p. 353-368.

WARREN, J. W. At what stage should energy be taught?. Physics Education, v. 21, n. 3, p. 154-155, 1986.

WERTSCH, J. V. Voices of the Mind: a sociocultural approach to mediated action. 4 ed. Cambridge: Harvard University Press, 1997. 